\title{
Matéria seca do feijoeiro e correção da acidez do solo em função de doses e fontes de corretivos
}

\author{
Dry matter of common bean and correcting of soil acidity in function of doses and sources of correctives \\ Fernando Shintate Galindo ${ }^{1}$, Juliano Costa da Silva ${ }^{1}$, Gustavo Antônio Xavier Gerlach ${ }^{1}$, Marina \\ Munhoz Rossato Ferreira ${ }^{1}$, Adriana de Souza Colombo ${ }^{2}$, Marcelo Carvalho Minhoto Teixeira Filho ${ }^{1}$
}

${ }^{1}$ Faculdade de Engenharia de Ilha Solteira (FEIS), Universidade Estadual Paulista "Júlio de Mesquita Filho" (UNESP), Departamento de Fitossanidade, Engenharia Rural e Solos (DEFERS), Rua Monção, 830, Ilha Solteira-SP. e-mail do autor correspondente: fs.galindo@bol.com.br

${ }^{2}$ Faculdade de Tecnologia de Jales (FATEC) "Professor José Camargo", Centro Paula Souza, Rua Vicente Leporace, 2630, Jardim Trianon, Jales -SP

\section{Recebido em: 02/06/2016}

Aceito em:21/07/2017

\begin{abstract}
Resumo. Novos produtos vêm sendo testados para melhorar o condicionamento do solo, entre eles o calcário líquido, que é um produto em suspensão com nano-partículas, centenas de vezes menores que as partículas do calcário convencional. Logo, torna-se necessário averiguar se realmente o calcário líquido é eficaz na correção da acidez do solo. Sendo assim, o objetivo deste trabalho foi avaliar o efeito de doses de corretivos de acidez líquido e em pó, na produção de matéria seca de feijoeiro irrigado e correção de um Latossolo Vermelho distrófico. O delineamento experimental foi em blocos ao acaso, com quatro repetições e em esquema fatorial $4 \times 2$, constituídos de quatro doses de calcário ( 0 (controle), $1 / 2 ; 1$ e $2 \times$ a dose recomendada) e dois tipos de corretivos de solo (calcário dolomítico em pó e calcário líquido). $\mathrm{O}$ comprimento da raiz principal, e as matérias secas de raiz e de parte aérea do feijoeiro não foram influenciados pelas doses e fontes de corretivo. $\mathrm{O}$ calcário dolomítico proporcionou maiores valores de $\mathrm{pH}$ do solo e menores acidez potencial, indicando que o corretivo líquido não foi eficaz na correção da acidez do solo. A aplicação de 2,7 t $\mathrm{ha}^{-1}$ de calcário dolomítico proporcionou a menor acidez potencial e o maior $\mathrm{pH}$ do solo cultivado com feijoeiro.
\end{abstract}

Palavras-Chave: acidez potencial, calagem, calcário líquido, Phaseolus vulgaris L., $\mathrm{pH}$ do solo.

Abstract. New products are being tested to improve the conditioning of soil, including liquid limestone, which is a product in suspension with nano-particles, hundreds of times smaller than the particles of conventional limestone. Therefore, it becomes necessary to establish whether the liquid limestone is effective for soil acidity correction. Thus, the aim of this study was to evaluate the effect of doses of acidity correctives liquid and powder, in the dry matter production of common bean irrigated and correction of an Oxisol dystroferric. The experimental design was in randomized blocks with four replications and in $4 \times 2$ factorial scheme, being four limestone doses (0 (control), 1/2, 1 and $2 \mathrm{x}$ the recommended dose) and two types of soil correctives (dolomitic limestone in powder and corrective liquid of acidity). The main root length, and dry matter of root and shoot of the common bean plant were not influenced by doses and corrective sources. The dolomitic limestone provided higher values of soil $\mathrm{pH}$ and lower potential acidity, indicating that the liquid corrective was not effective in correction of soil acidity. The application of $2.7 \mathrm{tha}^{-1}$ of dolomitic limestone provided the least potential acidity and the highest $\mathrm{pH}$ of the soil cultivated with common bean.

Keywords: potential acidity, liming, liquid limestone, Phaseolus vulgaris L., soil pH.

\section{Introdução}

O feijoeiro comum (Phaseolus vulgaris L.)

tem brasileiro, por ser considerado a principal fonte de proteínas da população de menor poder aquisitivo, e apresentar, ainda, como vantagem, a 


\section{Revista Agrarian}

ISSN: 1984-2538

possibilidade de cultivo em três diferentes épocas do ano, definidos como, cultivos "das águas", "da seca" e "de inverno" (Binotti et al., 2010; Calonego et al., 2010), contudo, os solos agrícolas brasileiros, em especial os Latossolos, por serem altamente intemperizados apresentam média a alta acidez, o que traz como consequência, a baixa produtividade das culturas, em decorrência da toxidez causada por alumínio (Al) e manganês $(\mathrm{Mn})$, deficiência de fósforo $(\mathrm{P})$ e pela baixa saturação por bases (V\%) (NÓIA et al., 2014). Neste contexto, a calagem visa elevar o $\mathrm{pH}$ e V\% e fornecer os nutrientes $\mathrm{Ca}$ e $\mathrm{Mg}$, influenciando diretamente na redução da toxidez de $\mathrm{Al}$ e podendo ainda alterar a disponibilidade de nutrientes no solo para as plantas (Pavinato e Rosolem, 2008; Soratto et al., 2010).

Além de provocar mudanças no $\mathrm{pH}$, teores de $\mathrm{Ca}, \mathrm{Mg}$ e $\mathrm{Al}$, aumentar a atividade biológica e a eficiência dos fertilizantes, a calagem nestes solos resulta ainda em aumentos das cargas dependentes de $\mathrm{pH}$ e, consequentemente, da $\mathrm{CTC}_{\mathrm{e}}$; diminuição na capacidade de adsorção de fósforo e indução, dependendo da quantidade e profundidade de incorporação, de um maior desenvolvimento do sistema radicular em profundidade, e sendo o feijoeiro uma cultura sensível à acidez (Rangel et al., 2009), a calagem tem sido prática indispensável para viabilizar o seu cultivo.

O calcário é o material disponível em maior quantidade no país para a correção de acidez, a calagem é a maneira mais fácil e barata de elevar o pH do solo (Souza et al., 2011). Contudo, o calcário necessita de tempo para reagir adequadamente no solo, e o ideal seria a sua incorporação ao solo, porém nem sempre é possível, ou seja, para que ocorra a reação em profundidade é necessário que o calcário se mova para camadas mais profundas, o que acarreta demora na reação do corretivo no solo (Churka Blum et al., 2013). Entretanto, pesquisas estão em andamento visando o desenvolvimento de novos produtos, e dentre eles destacam-se o carbonato de cálcio moído com partículas na granulometria nanométrica, como o recém-lançado calcário líquido (Assis et al., 2014; Nascente e Cobucci, 2015).

As principais vantagens do calcário líquido, são: o fácil manuseio e aplicação; bons teores de $\mathrm{Ca}$ e $\mathrm{Mg}$; não necessita incorporação no solo, apenas irrigação ou chuva; proporciona condições no solo para o aumento da eficiência dos fertilizantes aplicados; cria condições favoráveis para o aumento de produtividade das plantas (Braga, 2013).

Com isso faz-se necessário averiguar se os calcários líquidos são eficazes na correção da acidez do solo. Em estudo com aplicação no sulco de semeadura de calcário na forma líquida na cultura do feijoeiro, Nascente e Cobucci (2015), concluíram que a aplicação de solução de micropartículas de $\mathrm{CaCO}_{3}$ causa ligeiro aumento localizado, dos valores de $\mathrm{pH}$, e redução da saturação de Al no solo, além de proporcionar incrementos significativos do número de vagens por área e da produtividade de grãos do feijoeirocomum.

O objetivo deste trabalho foi avaliar o efeito de doses de corretivos de acidez líquido e em pó, na produção de matéria seca do feijoeiro irrigado e correção do solo.

\section{Material e Métodos}

$\mathrm{O}$ experimento foi realizado em casa de vegetação, no Departamento de Fitossanidade, Engenharia Rural e Solos, da Faculdade de Engenharia de Ilha Solteira - Unesp, Campus de Ilha Solteira, SP $\left(20^{\circ} 25^{\prime} \mathrm{S}, 51^{\circ} 20^{\prime} \mathrm{W}\right.$; $376 \mathrm{~m}$ de altitude), no período compreendido entre os meses de setembro a dezembro de 2014. A cultura implantada foi a do feijoeiro (Phaseolus vulgaris L.), do grupo carioca cv. IPR Tangará, que possui hábito de crescimento indeterminado, porte ereto e ciclo de aproximadamente 87 dias.

O solo utilizado foi classificado como Latossolo Vermelho distrófico, textura argilosa, segundo a Embrapa (2013), da camada de 0-20 $\mathrm{cm}$ de profundidade, o qual foi cultivado por culturas anuais há mais de 27 anos, sendo os últimos 10 anos em sistema plantio direto, sendo o trigo a cultura utilizada anteriormente. Este solo tipo de solo foi escolhido por representar a ordem, subordem e grande grupo do principal solo encontrado na região agricultável de Ilha Solteira -SP e Selvíria -MS, desta maneira refletindo as características de solo e simulando um sistema agrícola intensivo de produção de grãos, sob pivô central.

Foram efetuadas as análises químicas do solo anteriormente à aplicação dos tratamentos e 62 dias após a aplicação, seguindo a recomendação de Raij et al. (2001), apresentando os seguintes resultados, descritos na Tabela 1. 


\section{Revista Agrarian}

ISSN: 1984-2538

Tabela 1. Valores médios dos atributos químicos do solo anteriormente e 62 dias após a aplicação dos tratamentos. Ilha Solteira-SP, Brasil, 2014

\begin{tabular}{|c|c|c|}
\hline Análises & Antes da aplicação dos tratamentos & 62 dias após aplicação dos tratamentos \\
\hline$P_{\text {resina }}\left(\mathrm{mg} \mathrm{dm}^{-3}\right)$ & 39 & 65 \\
\hline M.O. $\left(\mathrm{g} \mathrm{dm}^{-3}\right)$ & 29 & 29,5 \\
\hline $\mathrm{K}\left(\mathrm{mmol}_{\mathrm{c}} \mathrm{dm}^{-3}\right)$ & 4,4 & 4,6 \\
\hline $\mathrm{Ca}\left(\mathrm{mmol}_{\mathrm{c}} \mathrm{dm}^{-3}\right)$ & 36 & 49 \\
\hline $\operatorname{Mg}\left(\mathrm{mmol}_{\mathrm{c}} \mathrm{dm}^{-3}\right)$ & 22 & 32 \\
\hline $\mathrm{SB}\left(\mathrm{mmol}_{\mathrm{c}} \mathrm{dm}^{-3}\right)$ & 62,4 & 85,6 \\
\hline $\mathrm{S}\left(\mathrm{mg} \mathrm{dm} \mathrm{m}^{-3}\right)$ & 13 & 16 \\
\hline CTC $\left(\right.$ mmol $\left._{c} \mathrm{dm}^{-3}\right)$ & 94,4 & 111,6 \\
\hline$V(\%)$ & 66 & 77 \\
\hline $\mathrm{B}\left(\mathrm{mg} \mathrm{dm}^{-3}\right)^{*}$ & 0,18 & 0,21 \\
\hline $\mathrm{Cu}\left(\mathrm{mg} \mathrm{dm}^{-3}\right)^{*}$ & 10,8 & 10,5 \\
\hline $\left.\mathrm{Fe}(\mathrm{mg} \mathrm{dm})^{-3}\right)^{*}$ & 39 & 35,3 \\
\hline $\operatorname{Mn}\left(m g d^{-3}\right)^{*}$ & 144,6 & 133,2 \\
\hline $\left.\mathrm{Zn}(\mathrm{mg} \mathrm{dm})^{-3}\right)^{*}$ & 3,5 & 4,1 \\
\hline $\mathrm{pH}\left(\mathrm{CaCl}_{2}\right)$ & 5,4 & 5,9 \\
\hline $\mathrm{H}+\mathrm{Al}\left(\mathrm{mmol}_{\mathrm{c}} \mathrm{dm}^{-3}\right)$ & 32 & 26 \\
\hline $\mathrm{Al}\left(\mathrm{mmol}_{\mathrm{c}} \mathrm{dm}^{-3}\right)$ & 0 & 0 \\
\hline $\mathrm{m}(\%)$ & 0 & 0 \\
\hline
\end{tabular}

O delineamento experimental foi em blocos casualizados, com quatro repetições e em esquema fatorial $4 \mathrm{X} 2$, constituído por quatro doses de calcário (0 (controle), 1/2; 1 e 2x a dose recomendada) e dois tipos de corretivos de solo (calcário dolomítico em pó e calcário líquido) para as avaliações do feijoeiro. Para as avaliações de $\mathrm{pH}$ e $\mathrm{H}+\mathrm{Al}$ do solo utilizou-se o delineamento experimental em blocos casualizados, com quatro repetições e em esquema fatorial $4 \mathrm{X} 2 \mathrm{X} 7$, ou seja, adicionou-se apenas o fator época de avaliação, sendo este igual a sete épocas.

Simulando um sistema agrícola intensivo, sob pivô central, foram aplicados $2,57 \mathrm{t} \mathrm{ha}^{-1}$ de calcário dolomítico como a dose de referência para elevar a saturação por bases a $90 \%$, o que equivale a $1250 \mathrm{mg} \mathrm{dm}^{-3}$ ou $8750 \mathrm{mg}$ de calcário por vaso com capacidade de $7 \mathrm{dm}^{3}$ de solo. A dose de calcário líquido utilizada foi a indicada pelo fabricante, de $5 \mathrm{~L}$ do produto comercial por tonelada de calcário em pó recomendado pela análise química do solo, sendo aplicados 0,04375 $\mathrm{mL}$ por vaso com $7 \mathrm{dm}^{3}$ de solo.

O calcário dolomítico em pó apresentava $88 \%$ de PRNT, $28 \%$ de $\mathrm{CaO}$ e $12 \%$ de $\mathrm{MgO}$. O calcário líquido apresentava garantias de $23 \%$ de $\mathrm{CaO}, 18,2 \%$ de $\mathrm{MgO}$, densidade $1,8 \mathrm{~kg} \mathrm{~L}^{-1}, 16,5 \%$ de $\mathrm{Ca}, 11 \%$ de $\mathrm{Mg}$ e $46,7 \%$ de $\mathrm{CaCO}_{3}$.

O solo foi peneirado em malha de $4 \mathrm{~mm}$, seco ao ar e posteriormente acondicionado em sacos plásticos. As doses de calcário foram aplicadas nos sacos plásticos e incorporadas ao solo de forma manual. Posteriormente, as amostras de solo foram transferidas para os vasos, no dia 10/09/2014. A seguir, adicionou-se água em cada vaso, equivalente a $80 \%$ da água disponível total (ADT) por um período de incubação de 20 dias. Para os tratamentos que consistiram na aplicação de calcário líquido, o produto comercial foi aplicado em ocasião de semeadura do feijoeiro, dia 30/09/2014, sem incorporação prévia.

As sementes de feijão, cultivar Tangará, foram tratadas com o fungicida Thiram $(150 \mathrm{~mL}$ $100 \mathrm{~kg}^{-1}$ sementes), para o controle preventivo da antracnose (Colletotrichum lindemuthianum) e podridão-radicular (Rhizoctonia solani). Por ocasião da semeadura, foram aplicados $10 \mathrm{mg} \mathrm{dm}^{-}$ ${ }^{3}$ de $\mathrm{N}, 60 \mathrm{mg} \mathrm{dm}^{-3}$ de $\mathrm{P}_{2} \mathrm{O}_{5}$ e $30 \mathrm{mg} \mathrm{dm}^{-3}$ de $_{2} \mathrm{O}$ para todos os tratamentos, com as fontes ureia, 


\section{Revista Agrarian}

ISSN: 1984-2538

superfosfato triplo e cloreto de potássio, respectivamente. A semeadura foi realizada em 30/09/2014, utilizando-se três sementes por vaso e a emergência das plântulas ocorreu 5 dias após a semeadura, no dia 05/10/2014.

Uma semana após a emergência, foi realizado desbaste, para deixar uma planta por vaso. Aos 9 e 23 dias após emergência (DAE), foram efetuadas duas adubações nitrogenadas de cobertura, aplicando-se $70 \mathrm{mg} \mathrm{dm}^{-3}$ de $\mathrm{N}$ (ureia) em cada vaso, por adubação.

As temperaturas de 22 e $29{ }^{\circ} \mathrm{C}$ foram fixadas como mínima e máxima, respectivamente. A necessidade de irrigação foi detectada mediante pesagem diária de quatro vasos para cada dose de calcário, colocando-se água em quantidade suficiente para elevar a umidade a $100 \%$ da ADT sempre que o nível atingia $80 \%$ da ADT.

Quando o feijoeiro estava em florescimento pleno, aos $48 \mathrm{DAE}$, as plantas foram ceifadas e separadas em parte aérea e raízes, para as avaliações do comprimento da raiz principal por meio de uma régua graduada e posteriormente, $o$ material vegetal separado foi acondicionado em estufa de circulação de ar a $60{ }^{\circ} \mathrm{C}$ por $72 \mathrm{~h}$, pesado, obtendo-se assim os valores de matéria seca de parte aérea e raízes. Foram coletadas amostras compostas do solo de cada tratamento para análise química (Raij et al., 2001), aos 20, $27,34,41,48,55$ e 62 dias após a aplicação dos tratamentos.

Os resultados foram analisados pela análise de variância e teste de Tukey a $5 \%$ de probabilidade para comparação de médias das fontes de calcário e, ajustadas a equações de regressão para o efeito das doses e épocas de aplicação de calcário, utilizando-se o programa Sisvar.

\section{Resultados e Discussão}

O comprimento da raiz principal, a matéria seca de parte aérea e de raiz não foram influenciados pelo aumento das doses de corretivo, assim como pelas fontes de corretivos (Tabela 2), provavelmente em função dos bons teores de cálcio e da ausência do alumínio trocável que é fitotóxico.

Tabela 2. Comprimento de raiz, matéria seca de parte aérea e matéria seca de raiz do feijoeiro em função de doses e fontes de corretivos. Ilha Solteira - SP, Brasil, 2014

\begin{tabular}{|c|c|c|c|}
\hline Doses & Comprimento da raiz principal $(\mathrm{cm})$ & Matéria seca de parte aérea (g) & $\begin{array}{c}\text { Matéria seca de raiz } \\
\text { (g) }\end{array}$ \\
\hline Controle & $80,33^{\text {ns }}$ & $8,00^{\mathrm{ns}}$ & $0,72^{\mathrm{ns}}$ \\
\hline 0,5 & 54,83 & 7,64 & 0,63 \\
\hline 1 & 84,00 & 7,06 & 0,57 \\
\hline 2 & 78,83 & 8,19 & 0,80 \\
\hline \multicolumn{4}{|l|}{ Fontes } \\
\hline Pó & 74,17 a & $8,21 \mathrm{a}$ & $0,66 \mathrm{a}$ \\
\hline Líquido & 74,83 a & $7,55 \mathrm{a}$ & $0,70 \mathrm{a}$ \\
\hline D.M.S. $(5 \%)$ & 9,94 & 1,40 & 0,17 \\
\hline Média Geral & 74,50 & 7,88 & 0,68 \\
\hline C.V. $(\%)$ & 15,24 & 20,28 & 28,11 \\
\hline
\end{tabular}

. Médias seguidas de mesma letra na coluna não diferem pelo teste de Tukey a 5\% de probabilidade.

Segundo Leite et al. (2006), a calagem influencia no crescimento das culturas, já que reduz diretamente a toxidez de $\mathrm{Al}$, que restringe o crescimento radicular. Outro fator importante é a distribuição e a atividade das raízes, que determinam a quantidade de água e nutrientes absorvidos. Sendo o feijoeiro uma planta sensível à acidez (Rangel et al., 2009), a calagem tem sido prática indispensável para viabilizar o seu cultivo, embora as plantas possam apresentar mecanismos de tolerância à absorção de $\mathrm{Al}^{3+}$ que dependem da planta. Segundo Heinrichs et al., (2008), quando o $\mathrm{pH}$ se encontra na faixa adequada (entre 6,0 e 6,5 em água) a fixação simbiótica do $\mathrm{N}_{2}$ é mais eficiente e a fitotoxicidade do $\mathrm{Al}$ e Mn é nula, o que permite maior desenvolvimento do sistema radicular, tornando a planta mais apta para produzir em condições de déficit hídrico. Dessa maneira, propicia condições favoráveis ao crescimento e desenvolvimento das plantas, fato 


\section{(-)}

\section{Revista Agrarian}

ISSN: 1984-2538

este não verificado no presente trabalho, possivelmente em função do $\mathrm{pH}$ do solo encontrar-se muito próximo da faixa supracitada, o que permitiu adequado desenvolvimento da cultura, independentemente da calagem.

No trabalho de Silva et al. (2004), a calagem promoveu aumento do sistema radicular e da parte aérea das cultivares de feijoeiro Campeão 1, Carioca, FT-Bonito e Pérola, corroborando vários autores que verificaram $o$ efeito benéfico da calagem no crescimento radicular do feijoeiro em solos ácidos. Resultados semelhantes verificados por Sousa Júnior et al. (1998), em solução nutritiva, onde constataram que as cultivares de feijão Milionário e Mulatinho, na presença de $\mathrm{Al}$ e doses de $\mathrm{Ca}$ e de $\mathrm{Mg}$, aumentaram a produção de matéria seca do feijoeiro. Entretanto, diversos experimentos têm mostrado resposta diferenciada das culturas à calagem, com alguns trabalhos não apresentando respostas positivas no crescimento das plantas e desenvolvimento do sistema radicular. Isto se deve a tolerância de cultivares de feijão associado a diferentes níveis de acidez do solo.

Leite et al. (2006), estudando doses de calcário dolomítico em sistema de plantio direto verificaram que nos tratamentos em que foram utilizadas doses menores de calcário, houve maior presença de raízes na camada superficial, devido principalmente à neutralização parcial do $\mathrm{Al}^{3+}$. Tal comportamento também pode estar relacionado com a menor quantidade de calcário aplicada, desfavorecendo a movimentação física das partículas do corretivo para camadas subsuperficiais e, ou, com a maior disponibilidade de nutrientes e adequado conteúdo de água na camada mais superficial do solo. Embora no presente trabalho o comprimento da raíz principal, a matéria seca de raíz e de parte aérea não tenham sido influenciadas pelas doses de calcário, é possível verificar que, para o comprimento de raíz principal a dose normal foi numericamente superior as demais doses testadas, e para matéria seca de raíz e de parte aérea, a maior dose propiciou, numericamente valores superiores.

Diferentemente dos resultados encontrados no presente trabalho, Silva et al. (2012) trabalhando com as doses de calcário dolomítico $\left(0,1,8,3,6\right.$ e $\left.5,4 \mathrm{t} \mathrm{ha}^{-1}\right)$ e cultivares de feijão, verificaram incremento na produção de matéria seca de parte aérea. Schultz et al. (2011), trabalhando com doses de calcário dolomítico para elevar a saturação por bases para $30 ; 45 ; 60$; 75 e $100 \%(5,83 ; 11,29 ; 16,76 ; 22,23$ e 31,33 g $\mathrm{kg}^{-1}$, respectivamente) encontraram aumento significativo na produção de matéria seca pelo feijoeiro, a partir da menor dose de calcário dolomítico aplicada, sendo decrescentes os incrementos com a aplicação de doses maiores de calcário. Vale ressaltar que a diferença de magnitude de resposta à calagem se deve principalmente à acidez potencial e $\mathrm{pH}$ de cada solo. A tendência é de que um solo mais ácido apresente maior resposta à correção comparativamente a um solo menos ácido, embora mesmo em condições de $\mathrm{pH}$ no solo favoráveis (6,0 a 6,5 em água) seja possível observar o efeito benéfico da calagem, principalmente em função da elevação dos teores de $\mathrm{Ca}$ e $\mathrm{Mg}$, apesar disto não ter sido constatado no presente estudo, possivelmente em função da adaptabilidade do cultivar quanto a fertilidade inicial do solo, que para cultura do feijoeiro V\% indicado é de $70 \%$.

Tais resultados elucidam a questão de que o manejo adequado dos solos é baseado na manutenção do $\mathrm{pH}$ evitando aplicação de elevadas doses de calcário. De acordo com Rossielo e Jacob Netto (2006), as plantas dicotiledôneas, como o feijoeiro, possuem em suas superfícies celulares alta densidade de cargas, as quais favorecem os íons trivalentes, como o $\mathrm{Al}$, a estabelecerem uma interação muito forte com estas superfícies, de maneira tal que praticamente entram em "colapso", formando ligações quase covalentes e, neste caso, dificilmente são substituídos nas superfícies de troca, reduzindo a capacidade de troca de cátions das raízes das plantas. A permanência do Al nesses sítios interfere no alongamento das raízes, na absorção de nutrientes benéficos, principalmente, cálcio, que é um elemento indispensável para o funcionamento das membranas celulares, reduzindo, desta forma, o desenvolvimento da cultura. Quando o $\mathrm{pH}$ em $\mathrm{CaCl}_{2}$ do solo está acima de 5,5, todo o alumínio tóxico já foi precipitado, não afetando sobremaneira, o desenvolvimento radicular e consequentemente o crescimento e produtividade da cultura. Mesmo no controle, o pH em $\mathrm{CaCl}_{2}$ obtido após 20 dias de aplicação dos tratamentos apresentava-se maior que o preconizado como limitante ao desenvolvimento radicular pela presença de $\mathrm{Al}$ tóxico, justificando porque o Al tóxico não foi 


\section{Revista Agrarian}

ISSN: $1984-2538$

fator limitante no desenvolvimento da cultura do feijoeiro no presente trabalho.

Tabela 3. Valores médios de pH e acidez potencial do solo em diferentes épocas após aplicação de doses e fontes corretivos. Ilha Solteira - SP, Brasil, 2014

\begin{tabular}{lll}
\hline Doses & $\mathbf{p H}\left(\mathbf{C a C l}_{\mathbf{2}}\right)$ & $\mathbf{H}+\mathbf{A l}\left(\mathbf{m m o l}_{\mathbf{c}} \mathbf{d m}^{-\mathbf{3}}\right)$ \\
\hline 0 & 5,66 & 28,93 \\
0,5 & 6,01 & 24,46 \\
1 & 5,93 & 25,32 \\
2 & 5,79 & 27,64 \\
\hline Épocas & & \\
\hline $30 / 09 / 2014$ & 5,87 & 26,94 \\
$07 / 10 / 2014$ & 5,93 & 26,00 \\
$14 / 10 / 2014$ & 6,01 & 23,88 \\
$21 / 10 / 2014$ & 5,92 & 25,94 \\
$28 / 10 / 2014$ & 5,86 & 26,69 \\
$04 / 11 / 2014$ & 5,76 & 27,56 \\
$11 / 11 / 2014$ & 5,56 & 29,13 \\
\hline Fontes & & \\
\hline Pó & 6,02 & 23,98 \\
Líquido & 5,67 & 29,20 \\
D.M.S. (5\%) & 0,05 & 0,78 \\
\hline Média Geral & 5,84 & 26,59 \\
C.V. (\%) & 2,03 & 7,78 \\
\hline
\end{tabular}

Médias seguidas de mesma letra na coluna não diferem pelo teste de Tukey a $5 \%$ de probabilidade.

As médias de $\mathrm{pH}$ e $\mathrm{H}+\mathrm{Al}$ em função das doses e fontes de corretivos e épocas de avaliação de $\mathrm{pH}$ e $\mathrm{H}+\mathrm{Al}$ do solo constam na Tabela 3. Houve interação significativa entre doses e fontes de corretivos para os valores de $\mathrm{pH}$. A fonte de corretivo em pó foi superior a fonte de corretivo líquida na meia dose, na dose cheia e na dose dupla (Tabela 4).

Tabela 4. Interação entre fontes e doses no pH do solo após aplicação de corretivos. Ilha Solteira - SP, Brasil, 2014

\begin{tabular}{ccccc}
\hline \multirow{2}{*}{ Fontes } & \multicolumn{5}{c}{ Doses } \\
\cline { 2 - 6 } & $\mathbf{0}$ & $\mathbf{0 , 5}$ & $\mathbf{1}$ & $\mathbf{2}$ \\
\hline Pó(1) & $5,66 \mathrm{a}$ & $6,34 \mathrm{a}$ & $6,14 \mathrm{a}$ & $5,95 \mathrm{a}$ \\
Líquido & $5,66 \mathrm{a}$ & $5,68 \mathrm{~b}$ & $5,71 \mathrm{~b}$ & $5,62 \mathrm{~b}$ \\
\hline D.M.S. & & \multicolumn{3}{c}{0,09}
\end{tabular}

Médias seguidas de mesma letra na coluna não diferem pelo teste de Tukey, a $5 \%$ de probabilidade. ${ }^{(1)} \mathrm{y}=5,7364+$ $1,0221 x-0,4643 x^{2}\left(R^{2}=0,70^{* *}\right)$.

Houve ajuste a função quadrática para doses apenas na fonte de corretivo em pó, sendo a dose ótima estimada $1,1\left(2,7 \mathrm{t} \mathrm{ha}^{-1}\right)$ próxima da dose recomendada $1\left(2,5 \mathrm{t} \mathrm{ha}^{-1}\right)$ para obtenção do maior $\mathrm{pH}$ do solo com feijoeiro, indicando assim que o corretivo líquido não foi eficiente para elevar o $\mathrm{pH}$ do solo.

Constatou-se também que a interação entre 


\section{Revista Agrarian}

ISSN: 1984-2538

épocas de avaliação e fontes de corretivos foi significativa para o $\mathrm{pH}$ do solo. O corretivo em pó propiciou valores de $\mathrm{pH}$ superiores em todas as épocas de avaliação, enquanto que, verificou-se ajuste das épocas à função quadrática tanto na fonte em pó quanto líquida (Tabela 5).

De maneira semelhante ao resultado verificado no comprimento da raiz principal, o corretivo na forma líquida não conseguiu atuar de forma satisfatória na correção do solo comparativamente ao calcário dolomítico em pó em função das doses aplicadas e também em função do tempo, diferentemente dos resultados obtidos por Nascente e Cobucci (2015), que trabalhando com doses de calcário líquido $(0$, $1.050,2.100,4.200,8.400$ e $12.600 \mathrm{~g} \mathrm{ha}^{-1} \mathrm{de}$ $\mathrm{CaCO}_{3}$ ) na cultura do feijoeiro verificaram que a aplicação de pequena quantidade de solução com calcário na forma de micropartículas elevou o $\mathrm{pH}$ do solo e reduziu a saturação de Al no sulco de semeadura, com reflexo positivo na produtividade de grãos da cultura.

Tabela 5. Interação entre fontes e épocas de avaliação do pH do solo após aplicação de corretivos. Ilha Solteira - SP, Brasil, 2014

\begin{tabular}{llllllll}
\hline \multirow{2}{*}{ Fontes } & Épocas & \multicolumn{7}{l}{} \\
\cline { 2 - 7 } & $30 / 09$ & $07 / 10$ & $14 / 10$ & $21 / 10$ & $28 / 10$ & $04 / 11$ & $11 / 11$ \\
\hline Pó $^{(2)}$ & $6,09 \mathrm{a}$ & $6,13 \mathrm{a}$ & $6,20 \mathrm{a}$ & $6,11 \mathrm{a}$ & $5,99 \mathrm{a}$ & $5,86 \mathrm{a}$ & $5,78 \mathrm{a}$ \\
Líquido $^{(1)}$ & $5,65 \mathrm{~b}$ & $5,74 \mathrm{~b}$ & $5,81 \mathrm{~b}$ & $5,73 \mathrm{~b}$ & $5,74 \mathrm{~b}$ & $5,66 \mathrm{~b}$ & $5,35 \mathrm{~b}$ \\
\hline
\end{tabular}

D.M.S. $\quad 0,12$

Médias seguidas de mesma letra na coluna não diferem pelo teste de Tukey a $5 \%$ de probabilidade. ${ }^{(1)} \mathrm{y}=5,4643+$ $0,2027 x-0,0304 x^{2}\left(R^{2}=0,91 * *\right) .{ }^{(2)} y=6,0179+0,1021 x-0,0202 x^{2}\left(R^{2}=0,95^{* *}\right)$

A interação entre doses e épocas também foi significativa para os valores de $\mathrm{pH}$, onde todas as doses avaliadas apresentaram comportamento quadrático em função da época de avaliação. $\mathrm{O}$ mesmo comportamento foi observado nas diferentes épocas de avaliação dentro de cada dose, onde as épocas de avaliação apresentaram comportamento quadrático em função das doses testadas (Tabela 6). Mesmo com a elevada V\% inicial do solo, é possível verificar o comportamento positivo do incremento das doses de corretivo em função da reação com as partículas do solo no decorrer do tempo, comprovando $\mathrm{o}$ benefício desta prática no aumento do $\mathrm{pH}$ e redução da acidez do solo.

Resultado semelhante verificado por Sousa et al. (2013), trabalhando com doses de calcário dolomítico $\left(0,1,2,3,4,5,8\right.$ e $\left.10 \mathrm{t} \mathrm{ha}^{-1}\right) \mathrm{em}$ Argissolo Vermelho-Amarelo distrófico, que verificou aumento do $\mathrm{pH}$ após 30 dias de aplicação dos tratamentos de 5,15 no controle para 7,26 na maior dose $\left(10 \mathrm{t} \mathrm{ha}^{-1}\right)$, corroborando o resultado observado por Silva et al. (2008) e Nicolodi et al. (2008) para amostras de Organossolos e Latossolo Vermelho distrófico respectivamente. Silva et al. (2004), trabalhando com doses de calcário dolomítico $(0 ; 1,59 ; 3,18 \mathrm{e}$ $4,48 \mathrm{t} \mathrm{ha}^{-1}$ ) e cultivares de feijoeiro (Campeão 1 ,
Carioca, FT-Bonito e Pérola), verificaram que o aumento das doses de calcário proporcionou elevação do $\mathrm{pH}, \mathrm{Ca}$ e $\mathrm{Mg}$ trocáveis e redução nos teores de $\mathrm{Al}$ trocável e $\mathrm{H}+\mathrm{Al}$, evidenciando o efeito positivo dessa prática.

Após 20 dias da aplicação dos tratamentos, o pH, em média, apresentava valores de 5,87 em $\mathrm{CaCl}_{2}$, com aumento aos 27 e 34 dias após aplicação chegando a 6,01 (Tabela 6). A partir dos 41 e 48 dias após a aplicação dos tratamentos, o $\mathrm{pH}$ apresentou ligeira queda, não diferindo do valor médio aos 20 dias após aplicação dos tratamentos, o que se deve a acidez propiciada pela nitrificação ocorrida após a adubação nitrogenada de cobertura na forma de ureia. A partir dos 55 e aos 62 dias após aplicação dos tratamentos, o pH apresentou pequena diminuição em seu valor, ou seja, provavelmente devido a maior absorção de nutrientes catiônicos, a qual libera $\mathrm{H}^{+}$para o solo, embora os valores de $\mathrm{pH}$ ainda estivessem superiores ao inicial de 5,4. O menor valor de $\mathrm{pH}$ do controle em relação aos demais tratamentos se deve não só à elevação do $\mathrm{pH}$ nos demais tratamentos proporcionados pela aplicação de corretivo, mas também a processos isolados ou combinados de reacidificação natural do solo oriundo da absorção de cátions básicos pelas culturas, pela mineralização da matéria 


\section{Revista Agrarian}

ISSN: 1984-2538

orgânica do solo e resíduos vegetais na camada

superficial (Leite et al., 2006).

Tabela 6. Interação entre doses e épocas de avaliação do pH do solo após aplicação de corretivos. Ilha Solteira - SP, Brasil, 2014

\begin{tabular}{lccccccc}
\hline \multirow{2}{*}{ Doses } & \multicolumn{7}{c}{ Épocas } \\
\cline { 2 - 7 } \multicolumn{1}{c}{} & $30 / 09^{(1)}$ & $07 / 10^{(2)}$ & $14 / 10^{(3)}$ & $21 / 10^{(4)}$ & $28 / 10^{(5)}$ & $04 / 11^{(6)}$ & $11 / 11^{(7)}$ \\
\hline $0^{(8)}$ & 5,70 & 5,70 & 5,75 & 5,70 & 5,75 & 5,60 & 5,40 \\
$0,5^{(9)}$ & 6,00 & 6,13 & 6,18 & 6,10 & 5,93 & 5,93 & 5,83 \\
$1^{(10)}$ & 5,95 & 6,00 & 6,13 & 6,00 & 6,00 & 5,85 & 5,55 \\
$2^{(11)}$ & 5,83 & 5,90 & 5,98 & 5,88 & 5,78 & 5,68 & 5,48 \\
\hline
\end{tabular}

${ }^{(1)} \mathrm{y}=5,727955+0,512045 \mathrm{x}-0,234091 \mathrm{x}^{2}\left(\mathrm{R}^{2}=0,82^{* *}\right){ }^{(2)} \mathrm{y}=5,749091+0,630909 \mathrm{x}-0,281818 \mathrm{x}^{2}\left(\mathrm{R}^{2}=0,70^{* *}\right){ }^{(3)}$ $\mathrm{y}=5,787500+0,737500 \mathrm{x}-0,325000 \mathrm{x}^{2}\left(\mathrm{R}^{2}=0,84 * *\right) .{ }^{(4)} \mathrm{y}=5,742955+0,627045 \mathrm{x}-0,284091 \mathrm{x}^{2}\left(\mathrm{R}^{2}=0,75^{* *}\right) .{ }^{(5)} \mathrm{y}=$ $5,747955+0,482045 \mathrm{x}-0,234091 \mathrm{x}^{2}\left(\mathrm{R}^{2}=0,99 * *\right) .{ }^{(6)} \mathrm{y}=5,632045+0,547955 \mathrm{x}-0,265909 \mathrm{x}^{2}\left(\mathrm{R}^{2}=0,82 * *\right) .{ }^{(7)} \mathrm{y}=$ $5,470227+0,449773 \mathrm{x}-0,229545 \mathrm{x}^{2}\left(\mathrm{R}^{2}=0,42 * *\right) .{ }^{(8)} \mathrm{y}=5,557143+0,132143 \mathrm{x}-0,021429 \mathrm{x}^{2}\left(\mathrm{R}^{2}=0,89^{* *}\right) .{ }^{(9)} \mathrm{y}=$ $5,953571+0,108036 \mathrm{x}-0,018750 \mathrm{x}^{2}\left(\mathrm{R}^{2}=0,81 * *\right) .{ }^{(10)} \mathrm{y}=5,746429+0,215774 \mathrm{x}-0,034226 \mathrm{x}^{2}\left(\mathrm{R}^{2}=0,95 * *\right) .{ }^{(11)} \mathrm{y}=$ $5,707143+0,153571 \mathrm{x}-0,026786 \mathrm{x}^{2}\left(\mathrm{R}^{2}=0,98^{* *}\right)$.

$\mathrm{O}$ pH do solo ideal, para a absorção da maioria dos nutrientes para a cultura do feijão, situa-se próximo de 6,0, como verificado neste trabalho. A diminuição dos valores de $\mathrm{H}+\mathrm{Al}$ e ausência de Al tóxico para as plantas, assim como aumento dos teores de $\mathrm{Ca}$ e valores estatisticamente iguais de $\mathrm{P}$, quando comparado com o solo sem aplicação de calcário, indicam que para os tratamentos aplicados não houve precipitação de $P$.

Para a acidez potencial, os valores em média, foram de $26,94 \mathrm{mmol}_{\mathrm{c}} \mathrm{dm}^{-3}$ após 20 dias da aplicação dos tratamentos, apresentando diminuição aos 27 e 34 dias após aplicação chegando a $23,88 \mathrm{mmol}_{\mathrm{c}} \mathrm{dm}^{-3}$ (Tabela 7). A partir dos 41 e 48 dias após a aplicação dos tratamentos, a acidez potencial apresentou ligeiro aumento, não diferindo do valor médio aos 20 dias após aplicação dos tratamentos. A partir dos 55 e aos 62 dias após aplicação dos tratamentos, a acidez potencial apresentou aumento em seu valor, ou seja, ocorreu a acidificação do solo conforme mencionado anteriormente para o $\mathrm{pH}$, embora os valores de acidez potencial ainda apresentavam-se inferiores ao inicial de $32 \mathrm{mmol}_{\mathrm{c}} \mathrm{dm}^{-3}$.

A interação entre doses e fontes de corretivos foi significativa para a acidez potencial. A fonte de corretivo líquida foi superior a fonte de corretivo em pó na meia dose, na dose cheia e na dose dupla. Não houve ajuste para o corretivo líquido, porém verificou-se ajuste a função quadrática para doses na fonte de corretivo em pó (Tabela 7), sendo a dose ótima estimada (2,7 tha $\left.{ }^{1}\right)$ próxima da dose recomendada $\left(2,5 \mathrm{t} \mathrm{ha}^{-1}\right)$ para obtenção da menor acidez potencial do solo com feijoeiro.

Tabela 7. Interação entre fontes e doses de corretivos na acidez potencial do solo. Ilha Solteira - SP, Brasil, 2014

\begin{tabular}{lllllll}
\hline \multirow{2}{*}{ Fontes } & \multicolumn{5}{c}{ Doses } \\
\cline { 2 - 6 } & & $\mathbf{0}$ & $\mathbf{0 , 5}$ & $\mathbf{1}$ & $\mathbf{2}$ \\
\hline Pó $^{(1)}$ & $28,93 \mathrm{a}$ & $19,79 \mathrm{~b}$ & $22,00 \mathrm{~b}$ & $25,21 \mathrm{~b}$ \\
Líquido & $28,93 \mathrm{a}$ & $29,14 \mathrm{a}$ & $28,64 \mathrm{a}$ & $30,07 \mathrm{a}$ \\
\hline D.M.S. & 1,57 & & & \\
\hline
\end{tabular}

Médias seguidas de mesma letra na coluna não diferem pelo teste de Tukey, a $5 \%$ de probabilidade. ${ }^{(1)} \mathrm{y}=27,9662-$ $14,5662 x+6,6753 x^{2}\left(R^{2}=0,76^{* *}\right)$.

A interação entre épocas e fontes de corretivos também foi significativa para a acidez potencial. A fonte de corretivo líquida apresentou valores de acidez potencial superiores estatisticamente em todas as épocas de avaliação, demonstrando assim, uma menor eficiência em 


\section{Revista Agrarian}

ISSN: 1984-2538

relação a calcário dolomítico. Houve ajuste para épocas de avaliação à função quadrática tanto na fonte em pó quanto líquida (Tabela 8), sendo que para ambos os corretivos, os menores valores de acidez potencial ficaram próximos da época 3 (34 dias após a calagem).

Tabela 8. Interação entre fontes e épocas de avaliação da acidez potencial do solo após aplicação de corretivos. Ilha Solteira - SP, Brasil, 2014

\begin{tabular}{llllllll}
\hline \multirow{2}{*}{\multicolumn{1}{c}{ Fontes }} & \multicolumn{7}{c}{ Épocas } \\
\cline { 2 - 8 } & $30 / 09$ & $07 / 10$ & $14 / 10$ & $21 / 10$ & $28 / 10$ & $04 / 11$ & $11 / 11$ \\
\hline Pó $^{(1)}$ & $24,00 \mathrm{~b}$ & $23,25 \mathrm{~b}$ & $21,25 \mathrm{~b}$ & $23,13 \mathrm{~b}$ & $24,63 \mathrm{~b}$ & $25,75 \mathrm{~b}$ & $25,88 \mathrm{~b}$ \\
Líquido $^{(2)}$ & $29,88 \mathrm{a}$ & $28,75 \mathrm{a}$ & $26,50 \mathrm{a}$ & $28,75 \mathrm{a}$ & $28,75 \mathrm{a}$ & $29,38 \mathrm{a}$ & $32,38 \mathrm{a}$ \\
\hline D.M.S. & 2,07 & & & & & &
\end{tabular}

Médias seguidas de mesma letra na coluna não diferem pelo teste de Tukey, a $5 \%$ de probabilidade. ${ }^{(1)} \mathrm{y}=24,7321$ $1,3333 x+0,2292 x^{2}\left(R^{2}=0,72 * *\right) .{ }^{(2)} y=31,9821-2,5119 x+0,3631 x^{2}\left(R^{2}=0,83 * *\right)$.

A interação entre doses e épocas também foi significativa para a acidez potencial, com ajuste à função quadrática para as doses controle, dose cheia e dose dupla, em função da época de avaliação, com menor teor de acidez potencial próximo da época 3 (34 dias após a aplicação da calagem). O mesmo foi observado avaliando-se as diferentes épocas de avaliação dentro de cada dose, onde ocorreu ajuste à função quadrática nas épocas de avaliação $2,3,4,5,6$ e 7 (27, 34, 41, 48,55 e 62 dias após aplicação da calagem), em função das doses aplicadas (Tabela 9).

Tabela 9. Interação entre doses e épocas de avaliação da acidez potencial do solo após aplicação de corretivos. Ilha Solteira - SP, Brasil, 2014

\begin{tabular}{|c|c|c|c|c|c|c|c|}
\hline \multirow{2}{*}{ Doses } & \multicolumn{7}{|c|}{ Épocas } \\
\hline & $30 / 09$ & $07 / 10^{(1)}$ & $14 / 10^{(2)}$ & $21 / 10^{(3)}$ & $28 / 10^{(4)}$ & $04 / 11^{(5)}$ & $11 / 11^{(6)}$ \\
\hline $0^{(7)}$ & 28,50 & 28,00 & 26,00 & 27,50 & 29,50 & 31,00 & 32,00 \\
\hline 0,5 & 25,50 & 23,75 & 22,00 & 24,75 & 25,25 & 24,25 & 25,75 \\
\hline $1^{(8)}$ & 26,25 & 25,75 & 22,00 & 24,50 & 24,00 & 25,75 & 29,00 \\
\hline $2^{(9)}$ & 27,50 & 26,50 & 25,50 & 27,00 & 28,00 & 29,25 & 29,75 \\
\hline
\end{tabular}

Com base nos resultados obtidos, o calcário líquido não seria recomendado como corretivo de acidez do solo, além de não beneficiar o desenvolvimento do sistema radicular e a produtividade de grãos da cultura do feijoeiro, diferentemente do que preconizam Nascente e Cobucci (2015), que concluíram que a aplicação de solução de micropartículas de $\mathrm{CaCO}_{3}$ causa ligeiro aumento localizado, dos valores de $\mathrm{pH}$, e redução da saturação de $\mathrm{Al}$ no solo, além de proporcionar incrementos significativos do número de vagens por área e da produtividade de grãos do feijoeiro-comum.

\section{Conclusões}

O comprimento da raiz principal, e as matérias secas de raiz e de parte aérea do feijoeiro não foram influenciados pelas doses e fontes de corretivo.

O calcário dolomítico proporcionou maiores valores de $\mathrm{pH}$ do solo e menores acidez potencial, indicando que o corretivo líquido não foi eficaz na correção da acidez do solo.

A aplicação de 2,7 $\mathrm{t} \mathrm{ha}^{-1}$ de calcário dolomítico proporcionou a menor acidez potencial e o maior $\mathrm{pH}$ do solo cultivado com feijoeiro. 


\section{(2) \\ Revista Agrarian \\ ISSN: 1984-2538}

\section{Referências}

ASSIS, R. T.; OLIVEIRA, I. J. V.; MORAIS, A. M. M.; NETO, A. A. M.; DIAS, S. H. Novas tecnologias para a agricultura brasileira. Araxá: Instituto de ciências da saúde, agrárias e humanas (ISAH), 7 p. (Circular Técnica, 02), 2014.

BINOTTI, F. F. S.; ARF, O.; CARDOSO, E. D.; SÁ, M. E.; BUZETTI, S.; NASCIMENTO, V. Fontes e doses de nitrogênio em cobertura no feijoeiro de inverno irrigado no sistema plantio direto. Bioscience Journal, v. 26, n. 5, p. 770$778,2010$.

BRAGA, G. N. M. Calcário para Aplicação na Forma Líquida. 2013. Disponível em: $<\mathrm{http}$ ://agronomiacomgismonti.blogspot.com.br/2 013/04/calcario-para-aplicacao-na-formaliquida_11.html > Acesso em 05 nov. 2014.

CALONEGO, J. C.; RAMOS JUNIOR, E. U.; BARBOSA, R. D.; LEITE, G. H. P.; GRASSI FILHO, H. Adubação nitrogenada em cobertura no feijoeiro com suplementação de molibdênio via foliar. Revista Ciência Agronômica, v. 41, n. 3, p.334-340, 2010.

CHURKA BLUM, S.; CAIRES, E. F.; ALLEONI, L. R. F. Lime and phosphogypsum application and sulfate retention in subtropical soils under notill system. Journal of Soil Science and Plant Nutrition, v. 13, n. 2, p.279-300, 2013.

EMPRESA BRASILEIRA DE PESQUISA AGROPECUÁRIA - Embrapa. Centro Nacional de Pesquisa de Solos. Sistema Brasileiro de Classificação de Solos. 3a ed. Brasília, DF: Embrapa, 353p, 2013.

HEINRICHS, R.; MOREIRA, A.; FIGUEIREDO, P. A. M.; MALAVOLTA, E. Atributos químicos do solo e produção do feijoeiro com a aplicação de calcário e manganês. Revista Brasileira de Ciência do Solo, v. 32, n. 3, p. 1157-1164, 2008.

LEITE, G. H. M. N.; ELTZ, F. L. F.; AMADO, T. J. C.; COGO, N. P. Atributos químicos e perfil de enraizamento de milho influenciados pela calagem em semeadura direta. Revista Brasileira de Ciência do Solo, v. 30, n. 4, p. 685-693, 2006.

NASCENTE, A. S.; COBUCCI, T. Calcário na forma de micropartículas aplicado no sulco de semeadura aumenta produtividade do feijoeiro.
Revista Ceres, v. 62, n. 6, p.597-606, 2015.

NICOLODI, M.; ANGHINONI, I.; GIANELLO, C. Relações entre os tipos e indicadores de acidez do solo em lavouras no sistema plantio direto na região do Planalto do Rio Grande do Sul. Revista Brasileira de Ciência do Solo, v. 32, n. 3, p. 1217-1226, 2008.

NÓIA, N. R. C.; CRUZ, M. C. P.; DAVALO, M. J.; OLIVEIRA, M. C.; FUJITA, C. K. Produção de matéria seca de alfafa (Medicago sativa $\mathrm{L}$.) em função de doses de calcário. Científica, v. 42, n., p. 310-315, 2014.

PAVINATO, P.C.; ROSOLEM, C. A. Disponibilidade de nutrientes no solo decomposição e liberação de compostos orgânicos de resíduos vegetais. Revista Brasileira de Ciência do Solo, v. 32, n. 3, p. 911- 920, 2008.

RAIJ, B. Van; ANDRADE, J.C.; CANTARELlA, H.; QUAGGIO, J.A. Análises químicas para avaliação da fertilidade de solos tropicais. Campinas: Instituto Agronômico, 285p, 2001.

RANGEL, A. F.; RAO, I. M.; HORST, W. J. Intracellular distribution and binding state of aluminum in root apices of two common bean (Phaseolus vulgaris) genotypes in relation to Altoxicity. Physiologia Plantarum, v. 135, n. 2, p.162-173, 2009.

ROSSIELO, R. O. P.; JACOB NETTO, J. Toxidez de Alumínio em Plantas. In: Fernandes, M. S. Nutrição Mineral de Plantas. Viçosa: Sociedade Brasileira de Ciência do Solo, p. 387390, 2006.

SCHULTZ, N.; LOSS, A.; PEREIRA, M. G.; BEUTLER, S. J.; ZONTA, E. Desenvolvimento de feijoeiro comum cultivado em amostras de Organossolo com diferentes níveis de calagem. Revista Ciência Agronômica, v. 42, n. 2, p.285291, 2011.

SILVA, E. B, SILVA, A. C., GRAZZIOTTI, P. H, FARNEZI, M. M. M., FERREIRA, C. A., COSTA, H. A. O., HORAK, I. Comparação de método para estimar a acidez potencial mediante determinação do pH SMP em organossolos da Serra do Espinhaço Meridional. Revista Brasileira de Ciência do Solo, v. 32, n. 5, p. 2007-2013, 2008. 


\section{(2) \\ Revista Agrarian \\ ISSN: 1984-2538}

SILVA, L. M. da; LEMOS, L. B.; CRUSCIOL, C. A. C.; FELTRAN, J. C. Sistema radicular de cultivares de feijão em resposta à calagem. Pesquisa Agropecuária Brasileira, v. 39, n. 7, p. 701-707, 2004.

SILVA, T. R. B. da; LEMOS, L. B.; CRUSCIOL, C. A. C.; FIORENTIN, C. F. Resposta de cultivares de feijoeiro comum à calagem superficial em semeadura direta. Semina: Ciências Agrárias, v. 33, n. 4, p. 1281-1290, 2012.

SORATTO, R. P.; CRUSCIOL, C. A. C.; MELLO, F. F. C. Componentes da produção e produtividade de cultivares de arroz e feijão em função de calcário e gesso aplicados na superfície do solo. Bragantia, v. 69, n. 4, p. 965-974, 2010.

SOUSA JÚNIOR, J. O.; NASCIMENTO, C. W. A.; MARTINEZ, H. E. P. Resposta do feijoeiro em solução nutritiva a níveis de cálcio e magnésio na presença de alumínio. Pesquisa Agropecuária Brasileira, v. 33, n. 7, p. 284-296, 1998.

SOUSA, L. F. R. A. de; MARINHO, R. W. D.; NUNES, F. M.; SILVA, R. V.; NASCIMENTO, I. O.; SILVA, W. A. da. Determinação do pH de um Argissolo Vermelho Amarelo distrófico incubado com aplicação de doses crescentes de $\mathrm{CaCO}_{3}$ por diferentes métodos. Revista Agroecossistemas, v. 5, n. 2, p. 58-63, 2013.

SOUZA, H. A.; NATALE, W.; ROZANE, D. E.; HERNANDES, A.; ROMUALDO, L. M. Calagem e adubação boratada na produção de feijoeiro. Revista Ciência Agronômica, v. 42, n. 2, p. 249-257, 2011. 